\title{
Redistribution and realization of energy at different scale-hierarchical levels of coalrock massif
}

\author{
Anna Sielski ${ }^{1}$, Kostiantyn Bezruchko ${ }^{2,}$, Liudmyla Pymonenko ${ }^{2}$, Oleksandr Burchak ${ }^{2}$, \\ Andrii Karhapolov, and Volodymyr Baranovskyi ${ }^{2}$ \\ ${ }^{1}$ Friedrich-Alexander University Erlangen-Nuremberg, 91054, Erlangen, Bismarckstrasse, 1a, \\ Germany \\ ${ }^{2}$ Institute of Geotechnical Mechanics named by N. Poljakov of National Academy of Sciences of \\ Ukraine, 49005, Dnipro, Simferopolska, 2a, Ukraine
}

\begin{abstract}
The research of redistribution and realization of energy at different scale-hierarchical levels at the Donbas coalrock massif based on the parameters of faultings and gas-dynamic phenomena has been conducted. It is proved that the energy transfer, incoming by impulses in post-inversion time of the geological development in Donbas, occurs throughout the whole structure of coal, due to the formation of energy connection between individual elements of the molecular structure. This process is accompanied by transition of free energy into a bound state with increase in ordering of the molecular structure and aromaticity of the coal substance (local increase in the degree of catagenetic transformations). The conditions of energy accumulation and realization depend on the peculiarities of molecular processes occurring in dislocations of different types. Less energy is accumulated in tensile zones than in compression zones, which is confirmed by the intensity of coal and gas outbursts. It has been established that the energy entering the multifractal geological environment in Donbas from external sources is also redistributed fractionally by the system, causing the formation of multiscale discrete inhomogeneities, which provides the massif with specific properties and ability to self-organization. A fractal model of the structure of the coalrock massif is proposed.
\end{abstract}

\section{Introduction}

The concept of energy, as well as substance, is the basis of ideas about geological processes. The amount of energy entering or generating as a result of structural-chemical processes in the coalrock massif and types of energy interaction determine massif state and provide mining-geological conditions of energy production. The degree of catagenetic transformations, the structure of the massif, the physicomechanical properties of rocks and coal, the orderly structure of the substance and the conditions for the formation of methane reserves characterize the state of the massif. Most of the energy that is entering during the

Corresponding author: gvrvg@meta.ua 
accumulation of sediments is used by organic substance for catagenetic transformations, and the rest is eventually dissipated into adjacent strata, involved in the formation of sedimentation disturbances and the activation of biochemical processes. Accordingly, the energy that was entering the massif in the post-inversion period and is entering today (during mining operations) consists of potential (accumulated previously) energy and energy of external impacts. The energy is spent on the permanent formation in the developing the basin through the formation of a multi-level system of faultings, including defects in the molecular structure of the substance and plastic deformations. It creates a modern structure of multiphase (solid, liquid and gaseous components) in the geological environment. But there are two various models of the geological environment to describe the structure of Donbas (the uneven distribution of folded deformations and faultings, the presence of areas of relative compaction, and decompaction of coal or rocks, which actually cause the energy saturation of the massif).

The first (wave) model is the structure of the massif in the form of blocks, separates with a ratio of linear sizes of different-scale blocks 0.5 [1]. And as the researches have shown, in Donbas this model is confirmed by the lateral repetition of positive and negative folds, compaction and decompaction zones in the coal beds [2]. According to the second model, the geological environment is a discrete scale-hierarchical system with a nonlinear fractional ratio in the linear dimensions of the individual blocks. The physical fields acting in this system form a hierarchical sequence of anomalies that correspond to various levels of the hierarchy. The mathematical expression of the self-similarity of such a system is the statistical laws, the fractal dimension of which varies from 2 to 3 [2-6]. This model is the most suitable for characterizing the location of faultings in Donbas that previous studies of faulting fractality show. It should be noted that the fractality assessments of the geological environment were carried out by many authors on various objects in scale $[3,5]$ and by various methods, so further detailed generalizations are needed.

Since fractures are both generators and accumulators of energy, the side characteristics of energy realization can be: the intensity of faultings, their genesis and distribution in the massif, or the presence of gas-dynamic phenomena.

The purpose of the paper is to research redistribution and realization of energy at various scale-hierarchical levels of the coalrock massif.

Donetsk coal deposit is a heterogeneous small-layer coalrock massif, disrupted by systems of different amplitude ruptures, the parameters and genesis of which are mainly described in detail, which makes it possible to study their distribution at different scale levels.

\section{Methodology}

The main parameters that quantify faultings are the amplitude, extension, width, and a number of dislocations, between which there are close relationships [5], that allow each of these parameters to be applied individually. However, since the amplitude and width of the fractures are not determined at the microlevel, the index of the faultings density $\left(K_{f}\right)$ is used as the same-type index at the various scale levels, which is equal to the ratio of the sum of lengths of fractures to the square area (sizes of the sides depending on the scope of the research).

To study the intensity of faultings in some geological-industrial districts, a methodology is developed and indexes $\left(K_{f}\right)$ are calculated based on geological data [5]. Fractures with amplitudes from $10 \mathrm{~m}$ to $10000 \mathrm{~m}$ are considered at the regional level in methodology, at the local one they are from 1 to $100 \mathrm{~m}$. Since the coalrock massif is a multiphase geological environment, geophysical data upon the velocity of longitudinal waves are used to characterize the total density of massifs; it is methane content of mine workings to assess 
gas saturation; it is the concentration of paramagnetic centers and the coefficient of aromatization to determine the coal micro-fracture.

According to the parameters measured by tectonic maps of the Donetsk Basin of different scale and plans of mining operations, the Hausdorff-Bezikovich method is applied for assessing the fractal dimension of faultings.

At the microlevel, researches are performed using the petrographic method on the video-optical complex (MBI - 11, HB 200, PC) on coal samples taken from medium carbon beds (rank $\mathrm{ZH}$ ). According to the characteristics of the dispersed composition and shape of the coal microparticles, according to the Jmage J program, the cellular fractal dimension is calculated.

At the nanoscale, the EPR method is used to determine the concentration of paramagnetic centers $N^{a}$ (defects in the electronic structure: unpaired electrons, that is, free radicals and defects in coupling systems). The coefficient of aromatization $\left(f_{a}^{E P R}\right)$, which characterizes the number and status of coupling systems in the molecular structure of the coal substance, is determined too. It also allows one to assess the activity and depth of the structural transformations (degree of structuring) of fossil organics at the molecular level.

\section{Discussion of the outcomes}

The modern configuration of faultings in Donbas was most actively formed after the inversion of the tectonic regime, when compressive forces with the shear component prevailed. The impulses of external forces, their sizes and directions set up local fields of stresses, in each of which dissipation of the obtained energy was carried out mainly due to the formation of dislocations and their subsequent combination, complication, growth, and merging. Differences of physical-mechanical properties of rocks and thermodynamic conditions led to the individual development of disturbance in different regions, districts (Table 1).

Table 1. Tectonic and structural characteristics (mean values) of the coalrock strata.

\begin{tabular}{|c|c|c|c|c|c|c|c|}
\hline \multirow[t]{2}{*}{$\begin{array}{l}\text { Geology- } \\
\text { industrial } \\
\text { district }\end{array}$} & \multirow{2}{*}{ 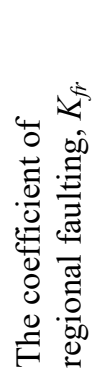 } & \multirow{2}{*}{ 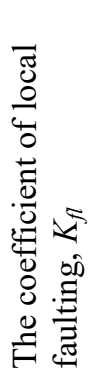 } & \multirow{2}{*}{ 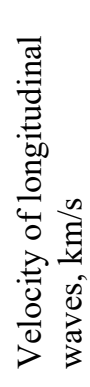 } & \multirow{2}{*}{ 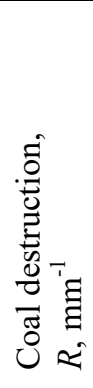 } & \multirow{2}{*}{ 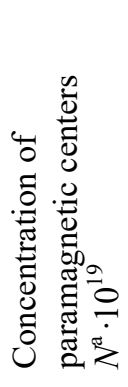 } & 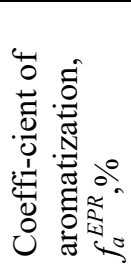 & $\begin{array}{l}\text { Relative } \\
\text { methane } \\
\text { content of } \\
\text { mine } \\
\text { workings, } \\
\mathrm{m}^{3} / \text { tonnes }\end{array}$ \\
\hline & & & & & & \multicolumn{2}{|c|}{ Rank coal ZH } \\
\hline Krasnoarmiiskyi & 0.59 & 0.026 & 4.08 & 7.8 & 48.3 & 2.3 & 14.7 \\
\hline $\begin{array}{l}\text { Donetsko- } \\
\text { Makiivskyi }\end{array}$ & 0.69 & 0.038 & 4.42 & 12.3 & 54.7 & 3.5 & 22.5 \\
\hline Tsentralnyi & 0.36 & 0.055 & 4.95 & 15.9 & 58.5 & 2.9 & 27.3 \\
\hline $\begin{array}{l}\text { Almazno- } \\
\text { Marivskyi }\end{array}$ & 0.62 & 0.56 & 4.62 & 10.5 & 59.1 & 2.2 & 22.6 \\
\hline
\end{tabular}

Tectonic and structural characteristics of the coalrock strata for the main geologicalindustrial districts in Donbas shown in Table 1 reflect the general tendency in changing the indexes at different scale levels. A sample of 190 value pairs has been statistically processed to determine the relationship between the faultings coefficients at different scales (regional and local). A linear correlation coefficient of 0.71 , with a reliability factor of 19.4 , 
indicates the interconnection of ruptured structures at different levels.

The analysis of the given data shows: 1) in more disturbance areas the coefficient of aromatization for the coal substance and the methane-bearing capacity of coal are also higher, which indicates a greater activity and intensity in developing the structural transformations; 2) coal of the same rank, formed in one-time period, depending on local conditions (genesis) is characterized by different structural indexes $\left(N^{a}\right.$ and $\left.f_{a}^{E P R}\right)$ at the molecular level.

The data required more detailed studies, since the formation of most of fractures occurred in the post-inversion period, when, according to many researchers, the structuring of the coal substance had already ended [7]. The EPR method is applied in conducting the works [8], the results of which indicate that with a change in pressure (up to $10 \mathrm{MPa}$ ) and temperature (up to $120^{\circ} \mathrm{C}$ ) the degree of structuring changes in the coal substance, that is, transformations arise similar to carbonaceous transformations at the pre-inversion stage. This can be explained by the fact that the energy entering the system as a result of the pulsed action of external forces contributes to its transition to a nonequilibrium state. The further transition of the system to the new equilibrium state occurs as a result of its energy unloading (the relaxation process of latent energy). At the same time, in the coal bed, relaxation is most efficiently due to the structuring of the coal substance, which is confirmed by the increase in structural parameters $\left(N^{a}\right.$ and $\left.f_{a}^{E P R}\right)$ in areas where more intense tectonic processes have occurred. Studies have proved that, under quasi-static conditions of undisturbed coalrock massif, the transformation of linear compounds into cyclic ones is energy-efficient, since it leads to redistribution and release of energy. In this case, energy connectivity is formed between the elements of the molecular structure of coal, that is, in amorphous coal substance, processes such as percolation take place [8]. By their physical nature, percolation processes are the transition of free energy into a bound state with increasing in the ordering of the molecular structure (aromaticity) of the coal substance. The transfer of energy throughout the structure of the molecule is accompanied by the execution of work (the formation of defects and micro dislocations, generation of methane and the structuring of solid organic matter). Therefore, in coal of the same degree of metamorphism and age after the inversion of the tectonic regime due to the redistribution of the energy of external forces, aromaticity of the coal substance in individual areas, beds, horizons or sites may change [9].

According to Griffiths theory, small-scale cracks consume more energy than they produce, but starting at some critical value, the effect becomes reversed. That is, disturbed zones are dissipative structures that can accumulate and discharge energy entering the massif. But the molecular structure of organic matter differs in various fractures by genesis. This fact is proved by studies of the molecular structure of the organic matter of coal by the EPR method in the tensile (fault), compression (thrust), and shear compression (kink band) zones. The concentration of paramagnetic centers in samples from the displacement of thrusts and kink bands is greater than in samples from undisturbed massif and faults. This can be explained by mechanical processes (friction) in the microstructure of coal under the external forces impact.

In Donbas, regional compressive efforts have been prevailing since the inversion of the tectonic regime. Tension occurs only in individual local sections. Free radicals arising on the surface of the fault displacement due to the destruction of intramolecular bonds, migrate and distribute in the expanded volume. This is confirmed by the absence of changes in the coefficients of aromatization of the carbonaceous organics. In paper [10] it was shown that under mechanical action generation of free radicals and their recombination were possible practically at any temperature. Resetting of the structure leads to the redistribution of energy in the substance, resulting in the formation of cracks and the formation of a transitional surface layer. It is characterized by a set of fractal dimensions in the distribution 
of geometric, energy, chemical and other properties. Its fractal dimension varies from 3 to 2 [11]. A decrease in the dimension $D$ of the substance distribution in space (when moving from the volume part with $d=3$ to the division surface with $d=2$ ) leads to the increasing the value of the energy component of the system. That is, on the "crack sides" energy is accumulated, which is proportional to the area of the division surface.

Unlike stretching, in the microstructure of thrusts, faults, or kink bands, complex combinations of particle motion occur relative to each other: rotations, friction displacements, bond breaks. Compression changes the nature of the structural transformations of coal macromolecules, intensity and scales of the transformations. Single hydrocarbon chains (or their parts) are destroyed or separated, allowing for more favorable conformations. The coal macromolecule breaks the valence bonds, reducing the content and length of the aliphatic chains, and the condensed aromatic structures are rearranged. Compression in the microstructure of the coal substance increases the number of defects in the formation of which excess energy is accumulated (or realized).

Obviously, at all hierarchical levels, the type of dislocations significantly affects the conditions of energy accumulation and realization: less energy is accumulated in tensile zones than in compression zones. Relaxation of accumulated energy leads to the separation of low molecular weight compounds by the free-radical mechanism according to the physicochemical model of transformations proposed in [9, 12-14]. Therefore, in a fractal geological environment, disturbed by a hierarchical system of raptures of different genesis and sizes, energy redistribution and usage also occurs unevenly, which determines the specificity of permanent accumulation, absorption and displacement of it at all scale levels, from the atomic-molecular to coalrock massif as a whole.

It is noted above that one of the signs of uneven energy accumulation in the massif is the manifestation of gas-dynamic phenomena: rock bumps, outbursts of coal, rocks and gas. Comparison of the location and intensity of coal and gas outbursts with fractures at the regional level shows that most of the outbursts are confined to fractures of different types (faults, thrusts, flexures, thickness changes, folds). In each area, the geological conditions of the occurrence of gas-dynamic phenomena differ. But in faults, their intensity is less than in the thrusts. So the average outburst capacity in the faults zones is $3-10$ tonnes; in the thrusts zones is 80-200 tonnes. A considerable amount of outbursts is confined to the areas of contorted coal, the formation of which is mainly related to the development of folds of longitudinal bending of different scale. Moreover, the outbursts are not confined to intensely disturbed areas (large raptures or periclinal parts of the folds), but to districts of average fracture. This allows us to conclude that a certain critical mass of disturbed (contorted) coal is required for outbursts occurrence. This assumption is confirmed by the results of the analysis of geological conditions for coal and gas outbursts in the Central district of Donbas. For example, at the $l_{3}$ and $k_{4}$ beds of the South Wing of the Main Anticline, all outbursts are recorded in areas of the increased capacity of the contorted patch of coal, but the greater the coal fracture in the bed is, the lower the outburst intensity is. Obviously, the energy accumulated in the molecular structure of the disturbed coal, under certain geological conditions, instantly activates the physico-chemical processes, in the form of chain free-radical reactions, which leads to the grinding of coal and the release of methane $[9,12-14]$.

Studies of the microstructure of coal in samples from undisturbed and disturbed zones, as well as the sections of beds where sudden outbursts occurred, proved that the fractal dimension (in the range of $1 \mu \mathrm{m}-1000 \mu \mathrm{m}$ ) for undisturbed coal was equal to $D=1.874$, for coal extracted from the zone of outburst and tectonic disturbance was the same and was equal to $D=1.757$; for undisturbed coal, from the ruptured zone (it occupied the middle position between the disturbed and undamaged coal) $D=1.820$. In undisturbed coal, the particle distribution is closer to lognormal, and in the disturbed coal and in outburst zones is 
closer to the stepwise law. In $[3,4,11]$ it is shown that the stepwise distribution is characteristic of complex systems whose components are formed as a result of long causeeffect relations and develop from one metastable state to another. Such distribution indicates the possibility for the formation of a state of self-organized criticality in the dynamics of an event. The study of complex systems having such property has shown [11] that they in themselves tend to a critical state and at every moment of time many elements release their energy simultaneously under the action of external impact. The energy release in such a system occurs very quickly and in quantities that far exceed normal values. According to statistics, the stepwise dependence is characteristic of earthquakes, tornadoes, hurricanes, and it indicates that catastrophic events occur rarely, but no special mechanism is needed to explain them. Obviously, in undisturbed or weakly disturbed parts there are significantly fewer possibilities for variations in the molecular transformations of the coal substance, the structure in them is more stable. In the outburst and disturbed areas, specific structuring of the coal substance (development of crack-porous structure, the formation of defects, etc.) occurs, and in this way, a set of possible states that the system can pass by responding to external conditions is laid in these zones. As the $D$ values decrease, with the increase of coal micro-disturbance, the amount of energy accumulated in the disturbed zones will increase, and the physico-chemical processes will be activated. But only in some beds, that at the micro level have a sufficient quantity of disturbed coal mass. Upon reaching the degree of destruction, which is characterized by $D_{\text {mikro }} \leq 1.757$ index, the system, under certain conditions, may go into a critical state and realize energy in the form of sudden coal and gas outbursts. These conclusions coincide with the results of the mininggeological analysis of the above-mentioned outburst conditions.

To research the structural model of the geological environment, fractal dimension calculations of raptured dislocations within the Donetsk basin were performed at various scale levels. Using the Hausdorff-Bezikovich method within five levels (from 0.01 to $1000 \mathrm{~m})$, the fractal dimension of the fractures $\left(D_{\text {makro }}=1.3\right)$ is calculated according to the tangent of a slope of the straight line, cracking $(D=1.60-1.74)$, a low-amplitude raptured fracture within single mines and sections $(1.18-1.31)$. Calculated on the points of manifestations of seismic phenomena at the O.F. Zasiadko mine values $D_{\text {makro }}$ (ranging from 10 to $10^{6}$ standard units) change from 1.17 to 1.58 .

By analogy, the fractal dimension of dependencies of lengths, the quantity of fractures, the surface area of displacements, distances between cracks on the scale of maps for single mines and workings, coal and sandstones were calculated. It is established that the distribution of the number of disturbances and their parameters in the coalrock massif is described by lognormal and stepwise laws, which indicates the fractality of the massif structure, and the differences of fractal dimensions at different scale levels - about its multifractality. The reliability of the obtained results is confirmed by the similarity of fractal dimensions calculated by different methods.

The obtained data allow us to represent the structure of the Donbas rock massif in the form of a self-similar scale-hierarchical model (Fig. 1).

The proposed fractal model of the structure for the coalrock massif is close to natural objects in the ratio of linear blocks. By this model, the geological environment represents a hierarchical system of similar blocks that are embedded one into another. That is, the external energy, which pulsed in and pulses into the massif after the inversion of the tectonic regime, forms a fractal geological environment. The uniqueness of the energyrelaxation relationship, which is inherent to the mechanics of a continuous medium in a fractal environment, is not fulfilled. Physical fields in such systems also form hierarchical sequences of anomalies that stimulate an uneven energy distribution. Moreover, the higher the density of dislocations in the plane, the greater their energy and the smaller the value of the fractal dimension $D$. The structure and behavior of such compound self-similar 
nonlinear dissipative systems is determined by different-scale discrete inhomogeneities that give them specific properties and the ability to self-identity.

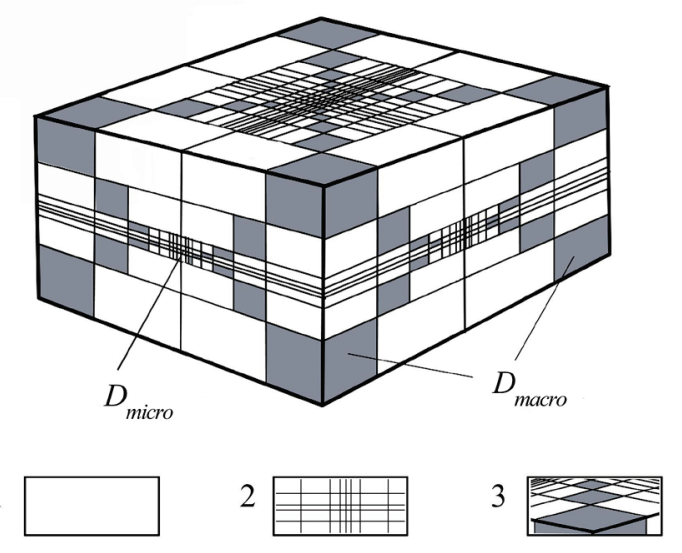

Fig. 1. Scale-hierarchical model of the structure for the coalrock massif: + rock massif -matrix; 2 - cracks system; 3 - self-similar blocks at different scale levels.

Thus, the fractality of the system radically changes its thermodynamic properties and kinetics of structural transformations and causes a variety of processes in the massif. In a fractal geological system, energy from external sources is consumed according to changes in the geometry of the system, that is, it is also redistributed fractionally by the system. At the regional level, the energy obtained performs work on the formation of the fractal structure of faultings, is partially lost, and partly accumulates at the molecular level and is spent on relaxation structural transformations of high molecular weight coal. At the molecular level, the energy of structural stresses is spent on relaxation conformational transitions, homolytic reactions of molecule rupture (free radical formation), isomerization, cyclization, polycondensation of a substance with the formation of the most thermodynamically stable hydrocarbon compounds - methane and cyclic fragments. In the fractal environment, relaxation occurs at all levels, but not all elements of the coal substance look toward the equilibrium with the same velocity, in addition, the geological environment has a scale-hierarchical structure, which causes unevenness and unpredictable energy distribution.

\section{Conclusions}

For the carboniferous strata of the Donetsk basin, the fractal dimensions of lengths and the number of rupture dislocations, the surface area of displacements, and the distance between the cracks of rocks at five levels (from 0.01 to $1000 \mathrm{~m}$ ) are calculated using the HausdorffBezykovich method.

It is found that according to geological data: the fractal dimension of the rapture is 1.30; the low-amplitude raptured fracture is $1.31-1.80$; cracking is $1.60-1.74$; according to seismological data of the O.F. Zasiadko mine. The fraction (in the range from 10 to $10^{6}$ standard units) values of fractal dimension change from 1.17 to 1.58 . The validity of the obtained results is confirmed by the similarity of fractal dimensions calculated by different methods.

Using experimental studies (EPR method) we have established the differences in the molecular structure of coal organic substance in the tensile (fault), compression (thrust), and shear compression (kink band) zones, demonstrating the different conditions of energy 
accumulation and realization in the coalrock massif.

It is substantiated that at the regional level the energy, obtained by the massif, performs work of creating the fractal structure of the coalrock massif. This energy is partially lost and partly accumulates at the molecular level and it is spent on relaxation conformational transitions, homolytic reactions of rapturing the molecules (formation of free radicals, isomerization, cyclization, polycondensation of the substance with the formation of the most thermodynamically stable hydrocarbon compounds (methane and cyclic fragments).

\section{References}

1. Tyapkin, K.F., Kivelyuk, T.T. (1982). Izuchenie razlomnykh struktur geologogeofizicheskimi metodami. Moskva: Nedra

2. Zabigailo, V.E., Lukinov, V.V., Pymonenko, L.I., Sakhnevich, N.V. (1994). Tektonika i gorno-geologicheskie usloviya razrabotki ugolnykh mestorozhdeniy Donbassa. Kyiv: Naukova dumka

3. Bulat, A.F., Dyrda, V.I. (2005). Fraktaly v geomekhanike. Kyiv: Naukova dumka

4. Shuman V.N., Kobolev, V.P., Starostenko, V.I., Bukrinskiy, I.B., Loyko, N.P., Zakharov, I.G., Yatsuta, D.A. (2012). A method of analysis of spontaneous electromagnetic emission of the Earth: physical backgrounds, elements of theory, field experiment. Geofizicheskiy Zhurnal, 4 (34), 40-61

5. Lukinov V.V., Pimonenko, L.I. (2008). Tektonika metanougolnykh mestorozhdeniy Donbassa. Kyiv: Naukova dumka

6. Mykulyak, S.V. (2018). Hierarchical block model for seismic processes. Dopovidi natsionalnoi akademii nauk Ukrainy, 11, 55-62. doi: http://doi.org/10.15407/ dopovidi2018.11.055

7. Geologiya mestorozhdeniy uglya i goryuchikh slantsev SSSR. Ugolnye basseyny $i$ mestorozhdeniya yuga Yevropeyskoy chasti SSSR (1963). Moskva: Gosudarstvennoe nauchnno-tekhnicheskoe izdatelstvo literatury po geologii i okhrane nedr, 1. 1209

8. Pymonenko, L.I., Burchak, A.V., Suvorov, D.A. (2014). Mehanizmy поглощения энергии угольным веществом на атомно-молекулярном уровне. Annual ScientificTechnical Collection - Mining of Mineral Deposits, 329-334

9. Bezruchko, K., Burchak, O., Balalayev, O. (2019). Gas generation by coal matter in contemporary condition. E3S Web of Conferences, International Conference Essays of Mining Science and Practice, 109 (2019). https://doi.org/10.1051/e3sconf/ 201910900006

10. Cherskiy, N.V., Tsarev, V.P., Soroko, T.I., Kuznetsov, O.L. (1985). Vliyanie tektonoseysmicheskikh protsessov na obrazovanie $i$ nakoplenie uglevorodov. Novosibirsk: Nauka

11. Shreder, M. Fraktaly, khaos, stepennye zakony. (2000). Izhevsk: Udmurtskiy universitet

12. Bulat, A.F., Bezruchko, K.A., Pimonenko, L.I., Burchak, O.V., Balalaєv, O.K. (2014). Nova fiziko-geologichna model genezisu vugilnogo metanu ta perspektivi ii zastosuvannya. Ugol Ukrainy, 4, 29-34

13. Bezruchko, K.A., Pymonenko, L.I., Burchak, A.V., Suvorov, D.A. (2018). Transformation of the energy state of the molecular structure of coal in the process of metamorphism. Journal of Geology, Geografy and Geoecology, 1 (27), 30-34

14. Burchak, A.V. (2017). Genezis gazoobraznykh uglevodorodov v ugleporodnom massive. Mining Magazine of Kazakhstan, 6, 16-19 